\title{
CORRESPONDENCE
}

\section{Incidence of pulmonary embolism in patients with COVID-19}

\author{
Tatiana Helena Rech ${ }^{1,2^{*}}$ (D) Adriana Muradás Girardi ${ }^{3}$ and Marcelo Basso Gazzana
}

(c) 2020 Springer-Verlag GmbH Germany, part of Springer Nature

\section{Dear Editor,}

We read with great interest the article by Helms and colleagues [1], "High risk of thrombosis in patients with severe SARS-CoV-2 infection: a multicenter prospective cohort study," published in Intensive Care Medicine in April 2020. In this interesting paper, the authors provide information on the incidence of thrombotic events, especially pulmonary embolism (PE), in patients with acute respiratory distress syndrome (ARDS) due to SARS$\mathrm{CoV}-2$ infection. This is an important topic that merits further discussion. We have noted a few points that may interfere with the interpretation of the results.

First, the reported incidence of PE of 25\% (including three cases of subsegmental PE) on computed tomography pulmonary angiography (CTPA) performed for suspected PE in patients with ARDS due to COVID-19 is not higher than expected. When a two-level classification of the pretest probability of PE is used, a $30 \%$ incidence can be predicted in the PE-likely category [2]. We published the results of a retrospective study showing a PE incidence of $30.4 \%$ in a medical population of critically ill patients undergoing CTPA for suspected PE [3]. Moreover, in a prospective study, the incidence of PE on CTPA performed for suspected PE was 39\% (Girardi et al., data in preparation). Taken together, these results point to a high incidence of PE in critically ill medical patients with respiratory failure, regardless of SARS-CoV-2 infection.

Second, PE is among the most commonly missed deadly diagnoses, possibly because of the low sensitivity and specificity of PE signs and symptoms. In fact, PE is a frequent finding in critically ill patients undergoing

*Correspondence: threch@hcpa.edu.br

${ }^{1}$ Unidade de Terapia Intensiva, Hospital de Clínicas de Porto Alegre, Porto Alegre, RS, Brazil

Full author information is available at the end of the article autopsy [4]. Historical controls might not have been considered to have PE, mainly outside the pandemic period, and, as expected, have not been subjected to investigation.

Third, D-dimer, a fibrin degradation product that increases in acute thromboembolic events has a very low specificity in the critically ill, because many clinical conditions associated with fibrin formation are present in intensive care unit (ICU) patients [5]. In our study, patients without $\mathrm{PE}$ had a median $\mathrm{D}$-dimer level of 3.3 $(0.2-36) \mathrm{mg} / \mathrm{mL}$, similar to $2.3(1.2-20) \mathrm{mg} / \mathrm{mL}$ observed in patients with Covid-19 in the study by Helms et al. [1].

Fourth, although prediction scores are not reliable for PE diagnosis in critically ill patients [3], efforts should be made to avoid overtesting with CTPA, as patients can be exposed to undesirable ionizing radiation doses, in addition to the risks of transportation out of the ICU [2]. In the study by Helms et al. [1], CTPA was performed in $66 \%$ of patients. Although the percentage of acceptable use of CTPA in critically ill patients is unknown, 66\% appears to be higher than recommended, mainly in a population with a well-defined alternative diagnosis to $\mathrm{PE}$.

In conclusion, historical controls are not the best control group. Despite the fact that we are facing new diagnostic and therapeutic challenges in patients with ARDS due to COVID-19, study design should be carefully considered in interpreting the results.

\section{Author details}

${ }^{1}$ Unidade de Terapia Intensiva, Hospital de Clínicas de Porto Alegre, Porto Alegre, RS, Brazil. ${ }^{2}$ Programa de Pós-Graduação Ciências Médicas: Endocrinologia, Universidade Federal do Rio Grande do Sul, Porto Alegre, RS, Brazil.

3 Programa de Pós-Graduação em Ciências Pneumológicas, Universidade 
Federal do Rio Grande do Sul, Porto Alegre, RS, Brazil. ${ }^{4}$ Serviço de Pneumologia, Hospital de Clínicas de Porto Alegre, Porto Alegre, RS, Brazil.

\section{Compliance with ethical standards}

\section{Conflicts of interest}

The authors declare they have no conflicts of interest.

\section{Publisher's Note}

Springer Nature remains neutral with regard to jurisdictional claims in published maps and institutional affiliations.

Accepted: 30 April 2020

Published online: 20 May 2020

\section{References}

1. Helms J, Tacquard C, Severac F, Leonard-Lorant I, Ohana M, Delabranche X, Merdji H, Clere-Jehl R, Schenck M, Fagot Gandet F, Fa-Kremer S, Castelain V, Schneider F, Grunebaum L, Anglés-Cano E, Sattler L, Mertes P-M, Meziani F, For the CRICS TRIGGERSEP Group (Clinical Research in Intensive
Care and Sepsis Trial Group for Global Evaluation and Research in Sepsis) (2020) High risk of thrombosis in patients in severe SARS-CoV-2 infection: a multicenter prospective cohort study. Intensive Care Med. https://doi. org/10.1007/s00134-020-06062-x

2. The Task Force for the diagnosis and management of acute pulmonary embolism of the European Society of Cardiology (ESC) (2019) ESC Guidelines for the diagnosis and management of acute pulmonary embolism developed in collaboration with the European Respiratory Society (ERS). Eur Heart J. https://doi.org/10.1093/eurheartj/ehz405

3. Girardi AM, Bettiol RS, Garcia TS, Ribeiro GLH, Rodrigues ÉM, Gazzana MB, Rech TH (2018) Wells and Geneva scores are not reliable predictors of pulmonary embolism in critically ill patients: a retrospective study. J Intensive Care Med. https://doi.org/10.1177/0885066618816280

4. Wiener RS, Schwartz LM, Woloshin S (2013) When a test is too good: how CT pulmonary angiograms find pulmonary emboli that do not need to be found. BMJ 347:f3368. https://doi.org/10.1136/bmj.f3368

5. Zhang $Y$, Xiao $M$, Zhang $S$, Xia $P$, Cao W, Jiang W, Chen $H$, Ding X, Zhao H, Zhang H, Wang C, Zhao J, Sun X, Tian R, Wu W, Wu D, Ma J, Chen Y, Zhang D, Xie J, Yan X, Zhou X, Liu Z, Wang J, Du B, Qin Y, Gao P, Qin X, Xu Y, Zhang W, Li T, Zhang F, Zhao Y, Li Y, Zhang S (2020) Coagulopathy and antiphospholipid antibodies in patients with Covid-19. N Engl J Med. https://doi. org/10.1056/NEJMc2007575 